\title{
HABITAÇÃO DE INTERESSE SOCIAL GENERATIVA: A GRAMÁTICA FORMA COMO INSTRUMENTO
}

\author{
GENERATIVE SOCIAL HOUSING. THE SHAPE GRAMMAR AS A DESIGN TOOL
}

\author{
Cristiana Griz ${ }^{1}$, Thaciana Belarmino ${ }^{1}$, Julia Dutra ${ }^{1}$
}

\section{RESUMO:}

Este artigo mostra a primeira etapa do desenvolvimento de um sistema generativo para conceber projetos de habitação de interesse social customizadas. O processo de construção de habitações geralmente envolve investimento para o desenvolvimento do projeto e para o gerenciamento do processo de construção. Em habitações desse tipo, muitas vezes o investimento é deixado de lado por razões econômicas. No entanto, devido à falta dele, o projeto pode não ser adequado e sua construção pode ser ainda mais onerosa e com baixa qualidade. Com o objetivo de contribuir para esta questão, este artigo apresenta a criação de um sistema generativo de projeto, uma gramática da forma, que possibilita desenvolver projetos de habitação de interesse social customizadas e que possa auxiliar na construção otimizada da edificação. O sistema segue os fundamentos e métodos descritos no formalismo da gramática da forma e é desenvolvido com base nas análises de projetos de reconhecido valor técnico, bem como em recomendações sobre projetos de habitação de interesse social de qualidade. Os resultados, ainda que parciais - referentes a primeira etapa do desenvolvimento da gramática, revelam a eficácia de sistemas generativos para a concepção de projetos customizados, e contribui para a busca da reinterpretação do processo tradicional de projeto / construção de habitações de interesse social.

PALAVRAS-CHAVE: Design generativo; gramática da forma; habitação de interesse social
Fonte de Financiamento: FACEPE

Conflito de Interesse: Declara não haver.

Submetido em: 20/04/2020 Aceito em: 08/07/2020

How to cite this article:

GRIZ, C.; BELARMINO, T. DUTRA, J. Habitação de Interesse Social Generativa: A gramática da forma como instrumento. Gestão \& Tecnologia de Projetos. São Carlos, v15, n3, 2020.

https://doi.org/10.11606/gtp.v15i3.168933 


\section{INTRODUÇÃO}

Esse artigo apresenta uma investigação que visa desenvolver um sistema generativo de projeto que sirva de base para a customização de projetos de habitação de interesse social. 0 foco é voltado à questão de projetos e construção de qualidade de algumas dessas habitações e contribui para o aperfeiçoamento de métodos que reinterpretem o tradicional processo de projeto.

0 processo de projeto e construção de habitações, independente do seu tamanho, geralmente envolve altos investimentos para o desenvolvimento do projeto e para o gerenciamento e execução da obra. Na sua própria definição, a habitação de interesse social é justamente aquela voltada à população que carece de recursos econômicos para ter acesso à moradia formal ou para contratar os serviços de técnicos profissionais da área. Esse investimento para o desenvolvimento e execução de tais projetos, que, na maioria dos casos, são duvidosos quanto a sua qualidade (BONDUKI, 2008; PINTO, PINTO, BERNARDO, FEIJÃO, 2017;FIM et al, 2019), acontece mais frequentemente no caso da criação de conjuntos habitacionais, seja por iniciativa pública, seja através de empresa privada. Quando a construção dessas habitações é feita de maneira isolada e a responsabilidade fica a cargo do seu próprio dono - a chamada autoconstrução (FIM et al, 2019), o investimento em projeto é, muitas vezes, deixado de lado por razões econômicas.

Entretanto, justamente pela falta de investimento e assessoria técnica especializada, o projeto pode não ser adequado, comprometendo sua qualidade e a construção pode resultar ainda mais onerosa. Segundo Amorim e Telles (2016), a autoconstrução é frequentemente encontrada em zonas urbanas e rurais de baixa renda, podendo resultar em projetos de habitações subdimensionadas, insalubre e sem os requisitos mínimos para uma moradia de qualidade. Sendo assim, grande parte das pessoas que conseguem adquirir um terreno nessas condições começam a construir suas habitações sem planejamento, sem o auxílio de um técnico que possa desenvolver um projeto adequado e, portanto, diminuindo a qualidade da construção, do ponto de vista técnico, estético e econômico.

Várias investigações são desenvolvidas com o objetivo de aumentar a qualidade de habitações de interesse social (MITCHELL 2008; BONDUKI, 2008; BUZZAR, FABRICIO, 2010; BRANDÃO 2011; MIRON, MONTEIRO, SILVA, 2019), principalmente aquelas produzidas pelo Programa Minha Casa Minha Vida (MCMV). Implementado em março de 2009, o MCMV foi criado com o objetivo de possibilitar que a população com rendimentos de até 10 salários mínimos pudessem ter acesso à moradia (NARDELLI, 2010; RANGEL, 2011). Sendo pensado principalmente para reduzir o déficit habitacional, ao final de um ano o programa também incentivou o crescimento da construção civil e o aquecimento do mercado imobiliário.

Entretanto, um dos recursos que o programa possibilita é pouco explorado por seus usuários. Além de financiar moradias já construídas por terceiros, o MCMV, na modalidade que ficou conhecida como "Entidade", também destina parte dos seus financiamentos para a construção de habitações para aqueles que adquirem um terreno em loteamento urbano. Para isso, a principal exigência é ter um projeto arquitetônico aprovado na prefeitura local - requisito importante e que faz com que as assessorias técnicas exerçam um papel fundamental para a construção de habitações de qualidade.

Como nessa camada da população poucos tem acesso a esse tipo de serviço, em 2008 foi criada a Lei no 11.888/2008, que assegura assistência técnica pública e gratuita para projeto e construção de habitação de interesse social. Contudo, como argumentam Fim e seus colegas (2019), depois de mais de dez anos da vigência da lei, poucos indícios de sua aplicação são 
verificados. Essa falta de acesso à assessoria técnica para a maioria dessa camada da população faz com que o de financiamento proposto pelo MCMV - Entidade fique ocioso.

Assim, tendo em vista esse nicho de mercado, e buscando contribuir com a qualidade desse tipo de habitação, a startup PopBIM do ramo da construção civil (incubada em 2018 no Porto Digital, Recife) buscou parceria com pesquisadores do Laboratório de Estudos Avançados em Arquitetura (lA2) e do Grupo de Estudos Modelagem da Informação do Ambiente Construído, ambos da Universidade Federal de Pernambuco (UFPE), para juntos, pensarem em um sistema que conceba projetos de alguns tipos de habitação de interesse social (ver características, descritas na Tabelas 1). 0 objetivo é desenvolver projetos de maneira generativa e que esse mesmo sistema auxilie na construção otimizada da edificação. 0 sistema é, portanto, centrado nos princípios do design generativo, mais especificamente a gramática da forma (descritos a seguir), que servirá de base para a geração customizada de projetos de habitação.

Tendo esta problemática como base, a investigação desenvolvida com parceria entre a PopBIM e a UFPE busca desenvolver e executar projetos de habitação de interesse social de qualidade de maneira otimizada. Isso será feito através do desenvolvimento de um sistema que vai facilitar o acesso a um projeto arquitetônico por essa camada da população, possibilitando a geração de projetos desenvolvidos dentro do princípio da gramática da forma. Além disso, ao final, pretende-se que esse sistema auxilie, também, a construção da habitação, através da mediação entre o proprietário e fornecedores de material e mão de obra da construção civil local.

De uma maneira geral, a gramática proposta é desenvolvida em três estágios:

1. $\quad 0$ estágio 1 diz respeito à organização espacial da habitação. Aqui, são definidas regras que dizem respeito à funcionalidade e resultam em diversas maneiras de organizar espacialmente os ambientes da habitação, de acordo com dados de entrada específicos, fornecidos pelo proprietário, como o número de ambientes, o tipo de interação entre eles (se mais restritivo ou mais interativo, como cozinhas abertas para a sala, por exemplo).

2. $\quad 0$ estágio 2 trata da volumetria do projeto. É desenvolvido necessariamente a partir da solução espacial selecionada no estágio anterior e guiado por outro conjunto de dados de entrada - altura do pé-direito, tipo de coberta, etc. Nesta fase, a mediação entre fornecedores já deve estar prevista e, de acordo as especificidades dos materiais, as regras de definição da volumetria serão inferidas.

3. $\quad 0$ estágio 3 é responsável pela definição dos elementos construtivos da habitação. Nesta fase são definidas as regras que irão decompor a volumetria definida no estágio anterior nos elementos construtivos da habitação - paredes, pisos, tetos, cobertas, esquadrias, etc. Aqui, pressupostos da fabricação digital serão levados em conta para a definição das regras.

Cada estágio, por sua vez, é desenvolvido em duas etapas: a parte analógica e a parte digital. A primeira mostra o processo de inferência de regras da gramática e o teste de aplicação dessas regras, através da derivação feita manualmente, regra por regra (como é visto a seguir) . A segunda faz uso de tecnologias digitais para implementar as regras de maneira que as soluções geradas pela gramática sejam obtidas de maneira automatizada e otimizada.

Este artigo apresenta a parte analógica do estágio 1 em um estudo piloto, onde é descrito o desenvolvimento da parte da gramática responsável pela distribuição funcional e organização espacial da habitação.

\section{SOBRE A GRAMÁTICA DA FORMA}

O século XXI é tido como a era das tecnologias digitais (KOLAREVIC, 2005). No campo da arquitetura e urbanismo, sua aplicação vai desde a adoção como ferramentas de representação 
- classificadas por Oxman (2006) como interação representacional, até a sua completa incorporação no processo de concepção do projeto - a chamada interação com o ambiente virtual (OXMAN, 2006). 0 nível de interação do projetista com essas tecnologias altera profundamente a maneira de pensar e o processo necessário para o desenvolvimento de projetos.

Neste cenário, o Design Generativo (DG), cujas bases conceituais e teóricas remontam da antiguidade clássica (MITCHELL, 1989), vem se consolidando juntamente com a disseminação e apropriação de novas tecnologias e ferramentas baseadas no uso do computador. Entretanto, por ser um termo que ficou mais conhecido devido a maior disseminação das tecnologias digitais, sua definição, muitas vezes, aparece de maneira confusa na literatura.

Sendo um dos temas do campo conhecido como "computacional design", o design generativo pode ser descrito como uma metodologia de projeto onde o projetista não interage diretamente na representação do projeto, e sim, com um sistema que representa o projeto (FISCHER; HERR, 2001). Para Celani (2011), um sistema generativo é um método indireto de projeto no qual o projetista não se preocupa apenas com a solução de um problema em particular em um contexto específico, mas em criar um projeto genérico, que possibilite resolver problemas semelhantes em contextos diferentes.

De acordo com o princípio do design generativo, o projetista cria um sistema de regras que, com sua implementação, digital ou analógica, vários projetos podem ser gerados. Neste paradigma as informações necessárias para conceber o projeto são organizadas e tratadas de acordo com os princípios definidos no sistema, que descreve o passo-a-passo para que o projeto seja desenvolvido. Quando essas regras são implementadas dentro de um sistema computacional, as soluções geradas são mais otimizadas, automatizadas e variadas. A aplicação de tecnologias computacionais na implementação é que acrescenta o caráter inovador para o design generativo. Assim, seu conhecimento e apropriação passa a ser de relevante importância para o campo de projetos de arquitetura.

Um dos sistemas generativos de projeto é a gramática da forma. Criada por Stiny e Gips (1972), ela consiste em um sistema de geração de formas baseado em regras que, aplicadas passo a passo (assim como os algoritmos ), são capazes de gerar uma linguagem de projeto (ELOY, 2012). Ou seja, com a aplicação de uma gramática da forma é possível obter vários projetos com características distintas, mas que possuem o mesmo princípio compositivo, definido pelas regras da gramática. É, portanto, um formalismo eficaz para se alcançar a customização em massa de projetos - principal produto a ser alcançado pela presente investigação.

Segundo Duarte (2007), um dos pioneiros no desenvolvimento de estratégias de personalização em projeto de habitações, a customização em massa permite oferecer produtos personalizados, em grandes quantidades, a custos similares aos de produtos padronizados e disponibilizados por meio da produção em massa. Prática já consolidada nas indústrias automotiva, aeronáutica e naval, a customização em massa aplicada a projetos unidade habitacionais pode trazer benefícios financeiros tanto para o cliente - que pode adquirir uma habitação adequada às suas demandas particulares, quando para o construtor, que passa a oferecer vários produtos personalizados sem precisar de mais investimentos para isso (NABONI; PAOLETTI, 2015).

A gramática da forma já vem sendo utilizada em vários projetos de habitações (DUARTE, 2007; MUSSI, 2014; ELOY, 2012; GRIZ, et al, 2016; LIMA, et al, 2017), evidenciando a mudança de paradigma no processo de projeto quando se deseja alcançar a customização em massa. Isso acontece, pois ela é utilizada como estratégia definidora das regras de concepção do projeto arquitetônico personalizado, como facilitadora da incorporação do usuário na concepção projetual, sendo, assim, promotora da personalização da unidade habitacional em série. 
Em geral, as gramáticas da forma podem ser classificadas de acordo com: (a) a maneira como as regras são inferidas e (b) a lógica da aplicação das regras. A primeira define as duas principais classificações descritas por Duarte (2007) - gramáticas originais e gramáticas analíticas. As analíticas são concebidas como uma ferramenta para analisar um grupo de projetos - o corpus, que definem uma única linguagem que os representa. Essa representação é feita por meio de regras inferidas a partir da análise dos próprios projetos que formam o corpus. Já as gramáticas originais são aquelas que geram novos projetos e as regras, neste caso, não são necessariamente criadas a partir da análise de projetos, mas podem, também, ser baseadas em requisitos pré-estabelecidos e descritos em textos, normas, etc.

Em relação à lógica da aplicação, as gramáticas podem ser de vários tipos (KNIGTH, 1999). As principais são as básicas (onde apenas as regras de adição são aplicadas), as não determinísticas (quando as regras da gramática são aplicadas em qualquer ordem), as sequenciais (onde as regras são aplicadas em uma ordem predefinida) e irrestrito (qualquer tipo de regra é aplicada em qualquer ordem).

Além dessas, alguns autores também sugerem que as regras podem ser aplicadas pelo método bottom-up ou top-down (MENDES, 2014). No método de desenvolvimento do sistema bottomup a solução é gerada a partir de uma forma inicial e uma lógica incremental, onde tem-se uma adição progressiva de outras formas agregadas a ela. Já nas gramáticas desenvolvidas segundo a lógica top-down, a solução formal é resultado da decomposição sucessiva da forma inicial em partes menores (Figura 1).

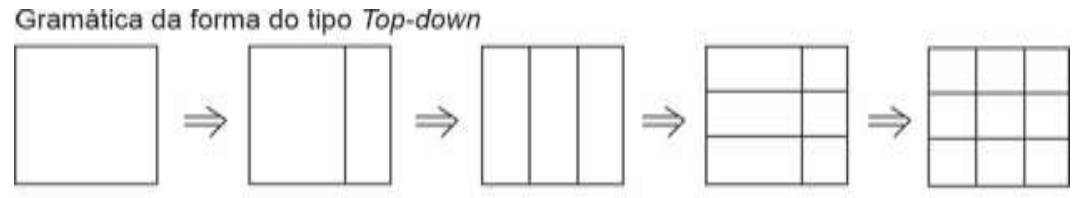

Gramática da forma do tipo Bottom-up
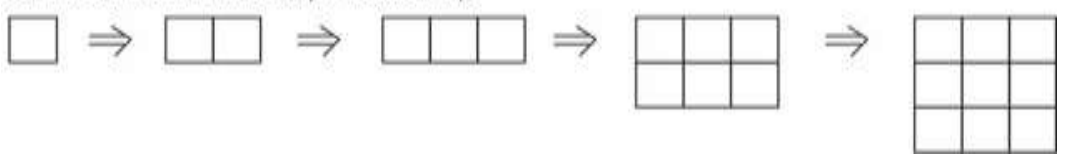

Independentemente do tipo, todas podem ser paramétricas. Uma gramática paramétrica é usada para codificar ordenadamente uma gama mais ampla de variações formais para a mesma regra. Ou seja, cada regra consiste em um conjunto de regras que podem codificar vários atributos da forma, para que uma maior variedade de parâmetros relacionados à forma possa ser combinada (ver regra L3, Figura 2).

Outro conceito de grande valia no desenvolvimento de gramáticas que envolvem muitos parâmetros para se chegar à solução formal final (como é o caso de gramáticas para projetos de arquitetura) é o de gramática genérica. Apresentado por Li (2001), a gramática genérica é aquela que nos primeiros estágios de desenvolvimento as regras são facilmente aplicáveis através de uma linguagem relativamente abstrata e, por essa razão, é capaz de gerar soluções em contextos distintos, de acordo com as especificidades do projeto. Em fases mais avançadas de desenvolvimento, as regras formais abstratas são revisadas e incrementadas com parâmetros e restrições de acordo com critérios específicos de cada contexto.

O primeiro estágio da gramática ora desenvolvida é parte analítica, outra parte, original, é também do tipo sequencial e desenvolvida segundo a lógica top-down. 0 resultado preliminar final (produto da aplicação das três primeiras etapas de desenvolvimento, como é visto a seguir) mostra o caráter genérico da gramática, que, ao ser finalizada, será toda paramétrica.
Figura 1: Exemplos de gramática da forma do tipo Top-Down (acima) e Bottom-up (abaixo).

Fonte: Os autores. 


\section{A GRAMÁTICA DA HABITAÇÃO GENERATIVA DE PEQUENO PORTE}

Como comentado, o estágio 1 de desenvolvimento da gramática tem foco na função e na geração de soluções que apresentem variadas organizações espaciais para a habitação. A primeira fase desse estágio resulta tanto de uma gramática analítica, quanto uma gramática original. Na primeira, o processo de inferência de regras contou com a análise de projetos de habitação de interesse social de reconhecido valor técnico e que foram objetos de pesquisas de alguns autores (ARAVENA; IACOBELLI, 2012; MAYER, 2012). Na segunda, às regras inferidas dos projetos de referência são acrescentadas outras resultantes de pesquisa e recomendações sobre projetos de habitação social (KOWALTOWSKI et al, 2015).

Dentre os projetos analisados, dois foram elaborados pelo escritório de arquitetura chileno, Elemental: (a) o Quinta Monroy e, (b) a Habitação Villaverde. Em ambos os casos, Aravena toma como partido a noção de arquitetura incremental - apenas um embrião inicial com áreas mínimas é entregue, ficando livre para cada usuário expandir de acordo com sua necessidade. Assim, estes projetos conseguem manter o equilíbrio entre baixos custos e personalização (ARAVENA; IACOBELLI, 2012).

Outra referência base para o desenvolvimento das regras da gramática é o trabalho desenvolvido por Mayer (2012). A autora argumenta que a padronização dos projetos é consequência da busca da redução de custos e do encurtamento do tempo de execução. Para combater a padronização, ela cria uma gramática da forma baseada num sistema modular adimensional que toma como partido as relações espaciais (relações de adjacência, circulação, aberturas, etc.). Mayer propõe, também, a abstração das restrições dimensionais, e trabalha com modelos espaciais topológicos extraídos do corpus estudado. Cria, assim, modelos matriciais a partir do qual é possível a geração de alternativas, criando, portanto, um extenso leque de opções a partir de um número limitado de regras.

Além desses, alguns dos princípios apresentados por trabalhos de referência no campo da arquitetura generativa para habitações (DUARTE, 2007; MUSSI, 2014; ELOY, 2012) serviram como base para a criação das regras da gramática proposta, como é visto a seguir.

\section{AS REGRAS DA GRAMÁTICA}

Para este estudo piloto foi feita uma parceria com empreendedores de um loteamento cujos terrenos apresentam área média de $200 \mathrm{~m} 2$. 0 terreno padrão do loteamento selecionado para estudo tem dimensões de $10 \mathrm{~m}$ x $20 \mathrm{~m}$, com frente ora para o Leste, ora para o Oeste.

A aplicação da gramática da habitação de pequeno porte segue basicamente quatro etapas, cada uma com seu conjunto de regras, que devem ser aplicadas exatamente na ordem apresenta - daí o caráter sequencial da gramática. São (a) as regras de implantação; (b) as regras de divisão de ambientes; (c) as regras de atribuição funcional e, (d) as regras de atribuição dimensional.

De uma maneira geral, uma gramática da forma é constituída por quatro componentes (STINY, 1976): (1) um conjunto de formas; (2) um conjunto de símbolos; (3) um conjunto de regras da forma e; (4) uma forma inicial. No desenvolvimento desta gramática, para cada etapa tem-se componentes distintos.

A primeira etapa apresenta um grupo de regras que define as opções de implantação da habitação no terreno. Como a gramática é top-down e o lote apresenta formato retangular, as formas utilizadas são retângulos e a forma inicial é aquela que define o formato do terreno, que será decomposto em retângulos genéricos menores. Já as regras e símbolos, neste caso, dizem respeito aos parâmetros relativos à orientação do terreno, às normas de afastamento e à área 
da habitação (Figura 2). 0 resultado dessa etapa apresenta o maior polígono onde a habitação pode ser locada no terreno: um retângulo com a maior área construída possível do pavimento térreo.

Como comentado, o loteamento apresenta terrenos voltados para o Leste ou para o Oeste. Assim, o primeiro conjunto de regras define a orientação do terreno (retângulo maior da Figura 2) através da aplicação da regra L1 ou da regra L2.
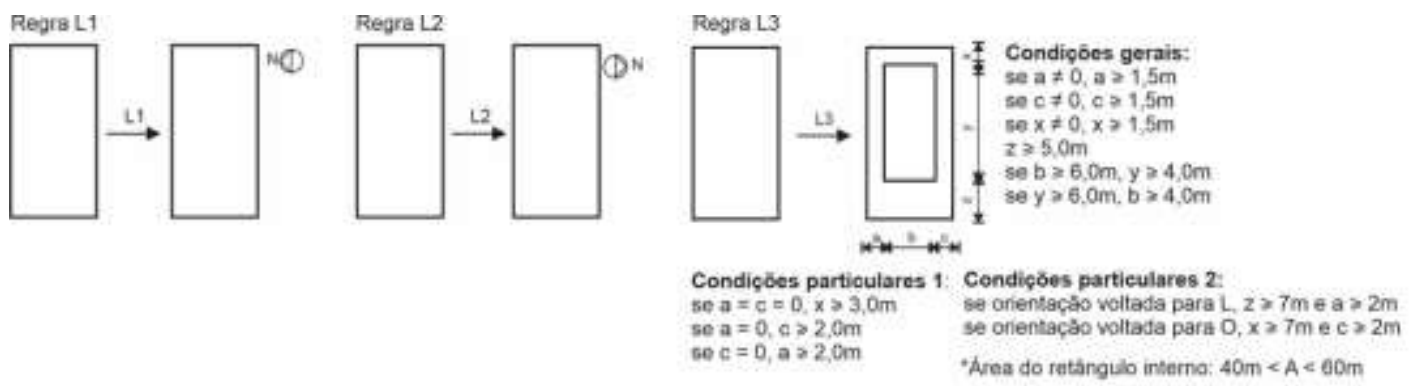

Com isso definido, aplica-se a regra L3 - uma única regra referente ao parâmetro urbanístico de afastamentos. Entretanto, por ser paramétrica, ela é capaz de gerar uma grande variedade formal, ao mesmo tempo em que atende às restrições descritas nas condições associadas a ela. As primeiras restrições, descritas nas condições gerais, são referentes às leis de afastamento definidas pela prefeitura local para esse tipo de loteamento e que geram uma implantação de edificação solta no terreno (o terreno é representado pelo retângulo maior e externo da Figura 2, e a projeção da edificação, pelo retângulo menor e interno). Porém, é possível que a edificação não tenha afastamentos em relação ao limite do terreno, caso atenda as condições particulares 1. Por fim, as condições particulares 2 definem afastamentos distintos dos apresentados nas condições gerais. Esses objetivam uma maior flexibilidade para a locação da edificação no lote, de maneira que esta possa proporcionar maior conforto em termos de ventilação e/ou insolação, ou mesmo para possibilitar a inclusão itens programáticos alternativos.

Vale ressaltar que alocação esquemática e provisória da habitação só pode ser definida quando o proprietário escolher o número de ambientes. Para esse estudo piloto foram definidas oito opções de programas arquitetônicos (Tabela 1). Estes variam em número de ambientes e apresentam algumas sugestões de pré-dimensionamentos, resultando na área média da habitação, que podem variar de $40 \mathrm{~m} 2$ a $80 \mathrm{~m} 2$. Com esse dado, e com a aplicação da regra paramétrica L3, é possível obter cinco possibilidades provisórias de locação da habitação (Figura 3). A edificação pode não apresentar afastamento na lateral direita ou esquerda do lote, pode estar solta no terreno ou não apresentar afastamento de fundo, nem nas duas laterais ao mesmo tempo.
Figura 2: Regras de orientação e afastamentos do lote.

Fonte: Os autores. 
Tabela 1: Área (em m2) e programa arquitetônico da habitação.

Fonte: Os autores.

\begin{tabular}{llll}
\hline Amblente & Min & Med & Max \\
\hline ESTAR & 7 & 8 & 9 \\
\hline IANTAR & 7 & 8 & 9 \\
\hline COZNHA & 6 & 6 & 6 \\
\hline BWC & 2 & 2 & 2 \\
\hline OUARTO 1 & 9 & 10 & 11 \\
\hline QUARTO 2 & 9 & 10 & 11 \\
\hline TOTAL & 40 & 44 & 49 \\
\hline
\end{tabular}

Seis ambientes.

\begin{tabular}{llll}
\hline Ambiente & Min & Ved & Max \\
\hline ESTAR & 8 & 9 & 10 \\
\hline JANTAR & 8 & 9 & 10 \\
\hline COZINHA & 7 & 7 & 7 \\
\hline BWC & 2 & 2 & 2 \\
\hline BWC & 2 & 2 & 2 \\
\hline QUARTO 1 & 9 & 10 & 11 \\
\hline QUARTO 2 & 9 & 10 & 11 \\
\hline TOTAL & 45 & 49 & 53
\end{tabular}

Sete ambientes com opção de dois banheiros e dois quartos.

\begin{tabular}{llll}
\hline Ambionte & Min & Uod & Max \\
\hline ESTAR & 9 & 10 & 11 \\
\hline IANTAR & 9 & 10 & 11 \\
\hline COZINHA & 4 & 4 & 4 \\
\hline COZINHA & 4 & 4 & 4 \\
\hline BUV & 2 & 2 & 2 \\
\hline QUARTO 1 & 9 & 10 & 11 \\
\hline QUARTO 2 & 9 & 10 & 11 \\
\hline QUARTO 3 & 9 & 10 & 11 \\
\hline TOTAL & 55 & 60 & 65
\end{tabular}

Oito ambientes com opção de duas cozinhas e três quartos.

\begin{tabular}{llll}
\hline Ambiente & Min & MeQ & MaX \\
\hline ESTAR & 10 & 11 & 12 \\
\hline JANTAR & 10 & 11 & 12 \\
\hline COZINHA & 5 & 5 & 5 \\
\hline COZINHA & 5 & 5 & 5 \\
\hline BWC & 2 & 2 & 2 \\
\hline BWC & 2 & 2 & 2 \\
\hline QUARTO 1 & 11 & 12 & 12 \\
\hline QUARTO2 & 11 & 12 & 12 \\
\hline TOTR & 56 & 60 & 62
\end{tabular}

Oito ambientes com opção de duas cozinhas, dois banheiros e dois quartos.

\begin{tabular}{llll}
\hline Ambiente & Mn & Mad & Max \\
\hline ESTAR & 8 & 9 & 10 \\
\hline JANTAR & 8 & 9 & 10 \\
\hline COZINHA & 4 & 4 & 4 \\
\hline COZINHA & 4 & 4 & 4 \\
\hline BWC & 2 & 2 & 2 \\
\hline CUARTO 1 & 9 & 10 & 11 \\
\hline QUARTO 2 & 9 & 10 & 11 \\
\hline TOTAL & 44 & 48 & 52
\end{tabular}

Sete ambientes com opção de duas cozinhas e dois quartos.

\begin{tabular}{llll}
\hline Ambiente & Men & Med & Max \\
\hline ESTAR & $\mathrm{g}$ & 9 & 10 \\
\hline JANTAR & $\mathrm{g}$ & 9 & 10 \\
\hline COZINHA & 7 & 7 & 7 \\
\hline BWC & 2 & 2 & 2 \\
\hline QUAARTO 1 & 9 & 10 & 11 \\
\hline QUARTO 2 & 9 & 10 & 11 \\
\hline QUARTO 3 & 9 & 10 & 11 \\
\hline TOTAL & 52 & 57 & 62
\end{tabular}

Sete ambientes com opção de três quartos.

\begin{tabular}{llll}
\hline Ambiente & Min & Med & MaAx \\
\hline ESTAR & 9 & 10 & 11 \\
\hline JANTAR & 9 & 10 & 11 \\
\hline COZINHA & 8 & 8 & 8 \\
\hline BWC & 2 & 2 & 2 \\
\hline BWC & 2 & 2 & 2 \\
\hline QUARTO 1 & 9 & 10 & 11 \\
\hline QUARTO2 & 9 & 10 & 11 \\
\hline QUARTO 3 & 9 & 10 & 11 \\
\hline TOTAL & 57 & 62 & 67
\end{tabular}

Oito ambientes com opção de dois banheiros e três quartos

\begin{tabular}{|c|c|c|c|}
\hline Amoiente & Min & fased & $\operatorname{Max}$ \\
\hline ESTAR & 11 & 12 & 13 \\
\hline IANIAR & 11 & 12 & 13 \\
\hline COZINHA & 6 & 6 & 6 \\
\hline OOZINHA & 6 & 6 & 6 \\
\hline BVC & 2 & 2 & 2. \\
\hline BWC & 2 & 2 & 2 \\
\hline QUARTO 1 & 10 & 11 & 12 \\
\hline QLIARTO? & 10 & 11 & 12 \\
\hline QUNRTO 3 & 10 & 11 & 12 \\
\hline TOTAL & 68 & 73 & 78 \\
\hline
\end{tabular}

Nove ambientes.

A segunda etapa define a partição dos ambientes na habitação. A forma inicial é justamente a planta de locação esquemática resultante da primeira etapa (Figura 3). As regras e símbolos (Figura 4) são referentes à dimensão dos lados do retângulo que representa a planta de locação e ao número e formato das suas partições da forma inicial. Devido ao caráter top-down da gramática, ela será subdividida em outros retângulos genéricos.

Figura 3: Exemplos de implantação esquemática da habitação no terreno, resultado da aplicação da regra paramétrica L3.

Fonte: Os autores.
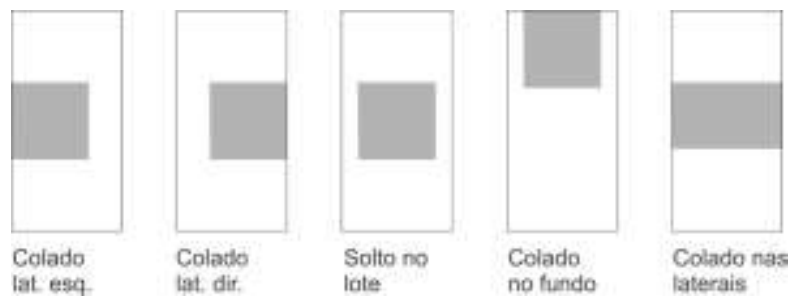
Como mostra a Tabela 1, as habitações podem variar de $40 \mathrm{~m} 2$ a $80 \mathrm{~m} 2$, apresentando de seis a nove ambientes, com possibilidade de combinação variada de funções. Com exceção da habitação com seis ambientes, cujos cômodos já são previamente definidos, o morador pode escolher o programa funcional da sua moradia, com opções de dois ou três dormitórios, com um ou dois banheiros ou com cozinha com dimensão mínima ou mais ampla. Seguindo esses critérios, o polígono resultante da implantação pode ser dividido, então, em seis a nove retângulos menores, cujas regras de subdivisão variam de acordo com o número de ambientes, a dimensão do polígono resultante da implantação e, em alguns casos, com a orientação do terreno (Figura 4).
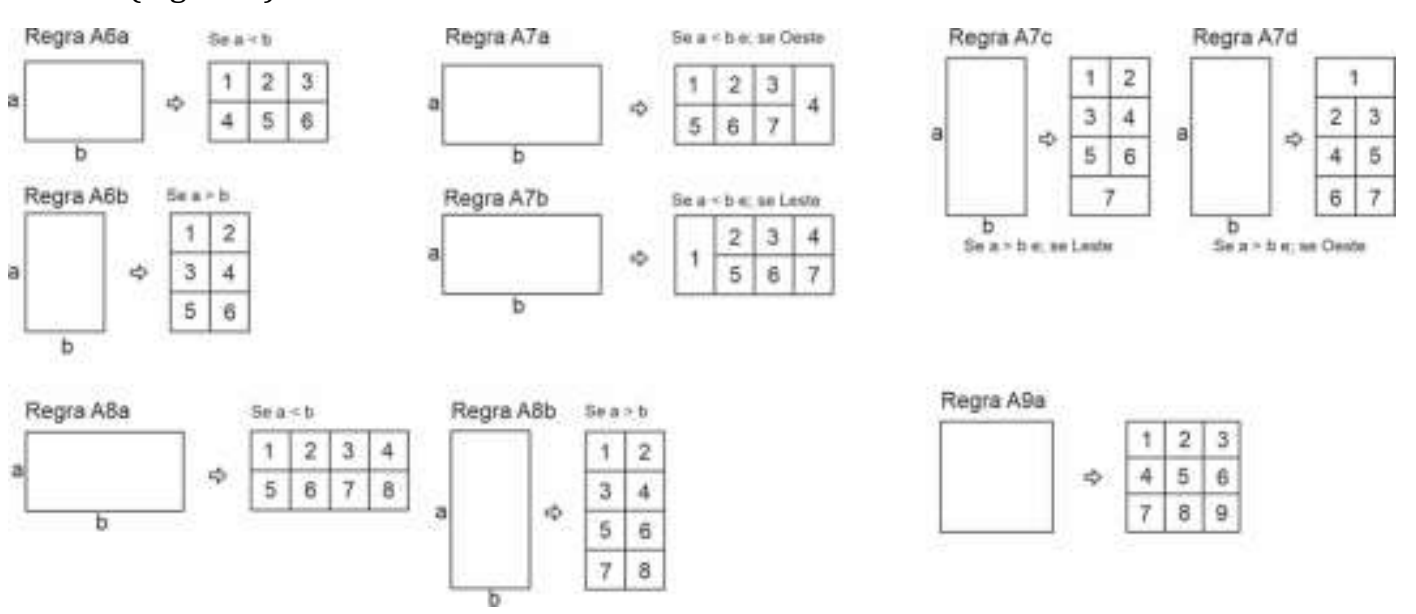

A terceira etapa se dedica a atribuir função a cada um desses ambientes. Isso é feito através de regras que apresentam marcadores. De uma maneira geral, em gramáticas da forma, um marcador (ou label) é um elemento que visa restringir a maneira que a regra pode ser aplicada (STINY, 1976). Neste caso, o marcador da gramática da habitação generativa de pequeno porte atribui a função que cada ambiente deve ter. Assim, as regras dessa etapa são feitas para modificar os marcadores que foram inseridos nas formas resultantes da etapa anterior, como mostra a Figura 5.

Distintamente de como sugeriu Mayer (2012), a primeira função que deve ser atribuída é a cozinha. Essa escolha se deu pela influência que ela exerce na localização dos demais cômodos da habitação, bem como por ser, juntamente com os banheiros, uns dos ambientes que tem maior custo de construção por m2. Em seguida vem a locação das salas, que, conforme análise do corpus, está adjacente à cozinha em $100 \%$ dos casos. A locação dos quartos e dos banheiros vem, respectivamente, logo em seguida.

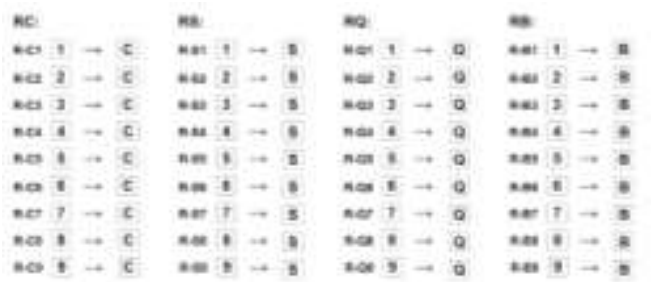

RC: Regra de alocação da cozinha RS: Regra de alocação da sala RQ: Regra de alocação do quarto RB: Regra de alocação do banheiro

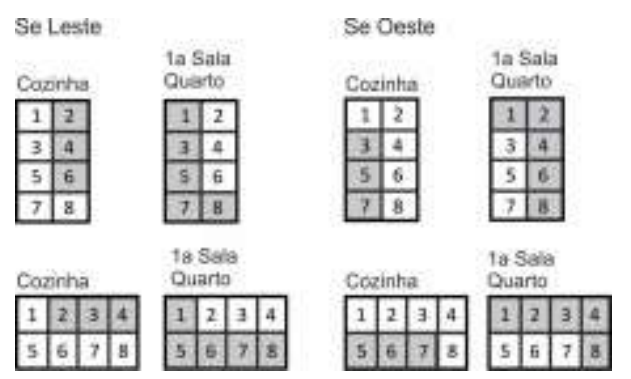


Vale destacar que a locação das funções depende não apenas do número de ambientes total da habitação, mas também (e como em todo projeto de arquitetura) da orientação do terreno. Nesse sentido, para cada opção de subdivisão de ambientes são definidas as posições possíveis que a cozinha, sala e quartos podem ser atribuídas (Figura 6). Essa definição facilitará a implementação computacional da gramática, uma vez que cada orientação apresenta um número limitado e específico de regras de atribuição de função, restringindo o número de regras que pode ser aplicado à medida em a gramática é gerada.

Para ilustrar, toma-se como exemplo um terreno cuja frente é voltada para o Leste, com oito ambientes e cujo polígono resultante da implantação tem largura menor que a profundidade (Figura 7). Para tal opção, a locação da cozinha, primeiro ambiente que deve ser posicionado, só pode ser feita nos ambientes número 2, 4 ou 6 (conforme indica a Figura 6). Ou seja, para esse exemplo, só podem ser aplicadas as regras de atribuição funcional R-C2, R-C4 ou R-C6 (descritas na Figura 5). Já a locação da sala, além de ter que estar adjacente à cozinha, só pode ser nos ambientes número 1, 3, 5, 7 ou 8. Para atender a esses critérios, apenas as regras de atribuição funcional R-S1, R-S3, R-S5, R-S7 ou R-S8, podem ser aplicadas, e assim sucessivamente.

A quarta e última etapa que forma o estágio 1 de desenvolvimento da gramática é responsável por definir as dimensões de cada um dos ambientes, sem alterar a relação de adjacência prédefinida. Apesar dessa etapa ainda estar em desenvolvimento, já foi definido que as dimensões dos ambientes tomarão por base as áreas discriminadas na Tabelas 1 - o que pode resultar numa infinidade de formatos de habitação, mesmo que, inicialmente, tenha-se como base apenas um esquema de subdivisão de ambientes, resultado típico do desenvolvimento de uma gramática da forma genérica.

\section{DERIVAÇÃO DA ORGANIZAÇÃO ESPACIAL DAS HABITAÇÕES}

O processo de derivação é uma importante ferramenta no desenvolvimento de uma gramática da forma (STINY, 1976). De maneira direta, a derivação mostra o passo a passo da geração de uma solução formal a partir da aplicação recursiva das regras. Entretanto, do ponto de vista do desenvolvimento e aprimoramento da gramática, ela serve para identificar regras que, embora distintas, sejam redundantes, podendo, assim, ser descartadas ou substituídas por regras mais eficientes.

Para exemplificar a aplicação passo a passo das regras da gramática da habitação generativa de pequeno porte é apresentada a derivação de um exemplo com oito ambientes (Figura 7), onde o proprietário optou por três dormitórios, sendo um, uma suíte. 0 terreno é voltado para o Leste (portanto, deve ser aplicada a da regra L2 da primeira etapa) e, como resultado da regra paramétrica de afastamentos (regra L3), o polígono resultante da implantação fica solto no lote. Esse polígono apresenta uma maior dimensão na profundidade do que na largura, fato que direciona a aplicação da regra A8a da terceira etapa para subdivisão dos ambientes (Figura 4).

Como o lote é voltado para o Leste e o polígono é mais profundo que largo, as posições possíveis para locar a cozinha são nos números 2, 4 ou 6. Assim, apenas as regras R-C2, R-C4 e R-C6 da terceira etapa podem ser aplicadas. A derivação apresentada na Figura 7 mostra o caminho percorrido a partir da escolha de uma dessas três regras, pois, devido ao caráter sequencial da gramática, as regras que podem ser aplicadas dependem diretamente da escolha da regra que a sucedeu. 


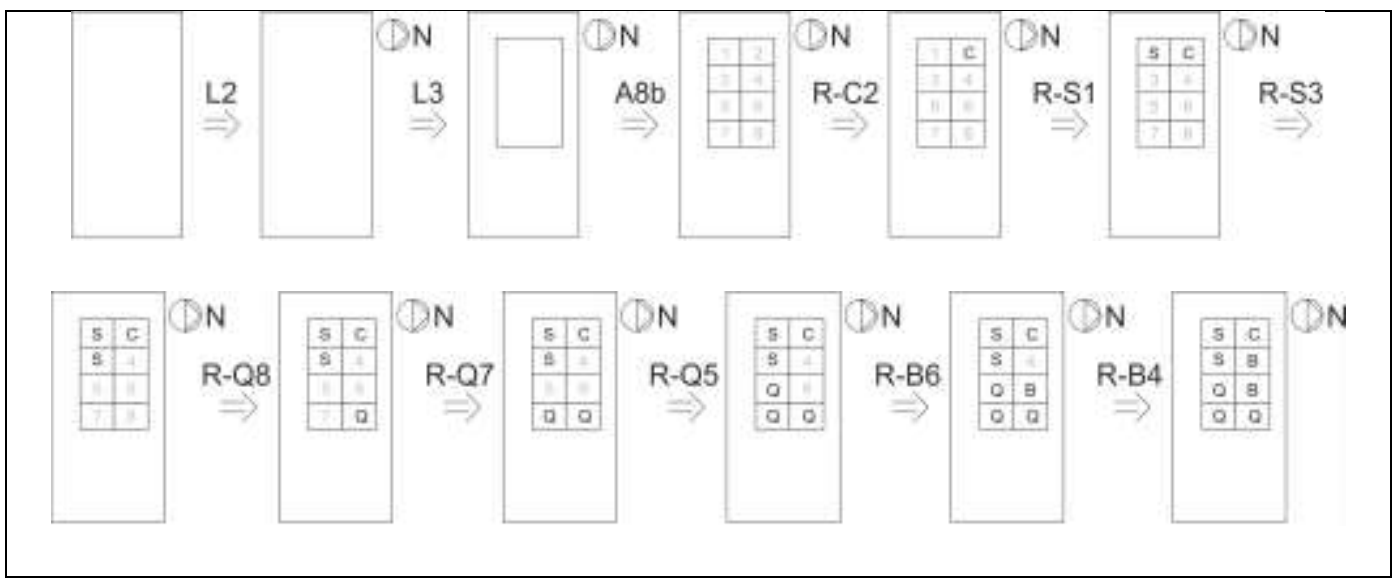

Figura 6: Exemplo de derivação.

Fonte: Os autores.

Esse é um exemplo de derivação que resultou em uma única solução de organização espacial esquemática da habitação. Entretanto, partindo da mesma forma inicial apresentada na Figura 7 , e com a escolha de regras distintas a cada passo da derivação, é possível obter várias outras soluções espaciais, como mostra a Figura 8. A partir da escolha do posicionamento da cozinha, o segundo ambiente a ser atribuído é a sala. Para esta orientação, a sala só é possível ser localizada nos números 1, 3, 5, 7 ou 8. No entanto, as definições das regras de posicionamento da sala dependem, também, da posição previamente escolhida para a cozinha, já que outra restrição é que os dois ambientes sejam adjacentes. Caso a cozinha tenha sido locada na posição 2, a sala só poderá ficar nos 1 ou 3 e apenas as regras R-S1 ou R-S3 podem ser utilizadas. Se a opção de posicionamento da cozinha tiver sido no número 6 , a sala pode ser locada nos $3,5,7$ ou 8, e, por isso, restringe a aplicação apenas às regras R-S3, R-S5, R-S7 ou R-S8.

E com essa lógica segue-se a sequência de atribuição do segundo ambiente referente à sala (estar e/ou jantar), dos quartos e dos banheiros - com a escolha da localização de um ambiente influenciando diretamente a localização do próximo. Como resultado, temos uma espécie de "árvore" que mostra as possíveis derivações ou os caminhos possíveis para se chegar à organização espacial da habitação. Para esse tipo de lote e o programa arquitetônico escolhido (oito ambientes com dois dormitórios e uma suíte), é possível gerar 12 organizações espaciais esquemáticas de habitações. 
Figura 7: Árvore de derivações que geram 12 organizações espaciais esquemáticas de habitações com oito ambientes (com dois dormitórios e uma suíte), cujo lote é voltado para 0 Leste.

Fonte: Os autores.

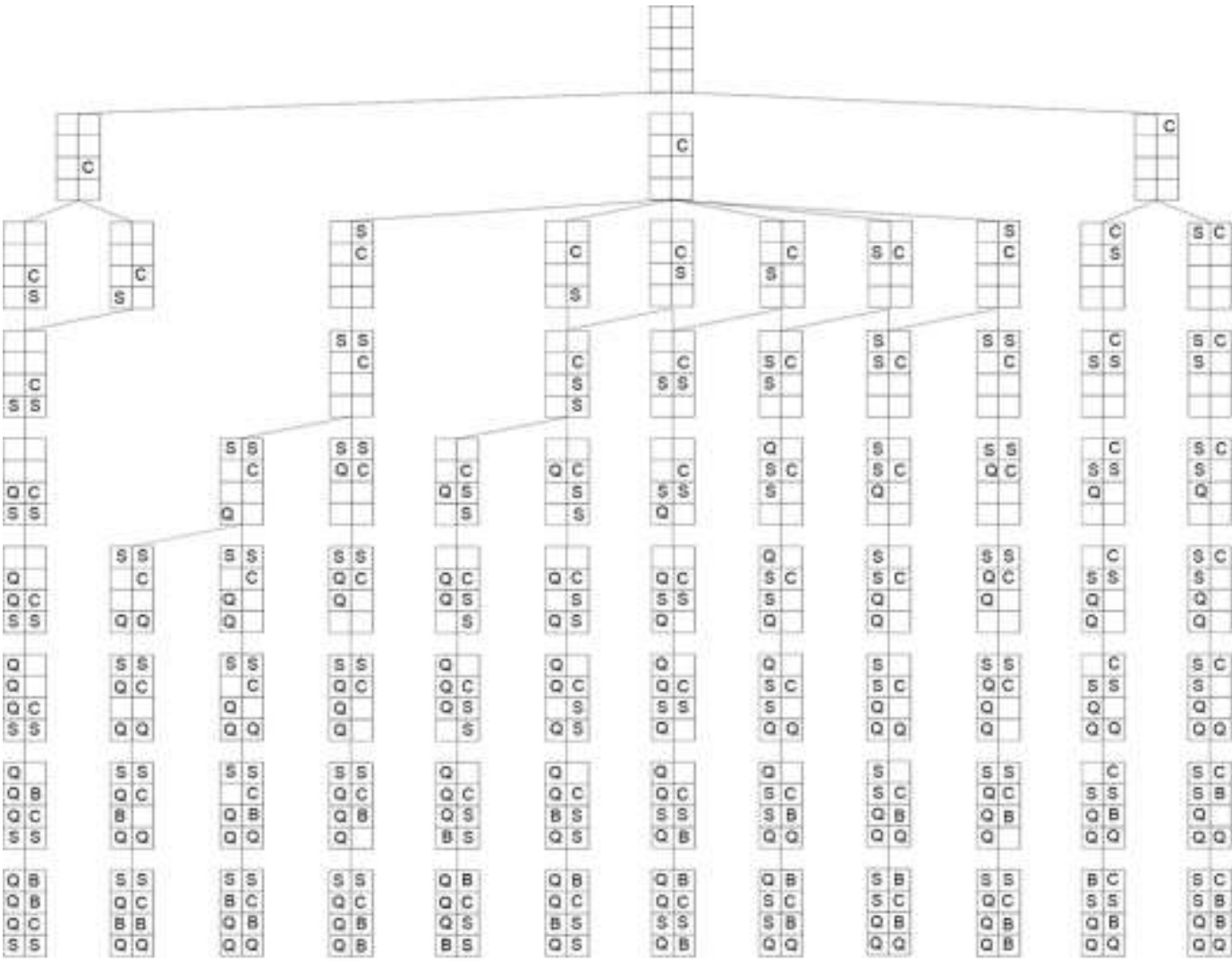

Como comentado, o resultado da aplicação das etapas até aqui apresentadas define a organização espacial genérica da habitação. No entanto, essa solução genérica é capaz de gerar um grande número de plantas distintas, dependendo do contexto das escolhas individuais dos proprietários feita nas etapas anteriores, mas que guardam as mesmas relações de adjacência. É por essa razão que as regras da quarta etapa - definição do formato e das dimensões dos ambientes (ainda em desenvolvimento), precisam ser, necessariamente, paramétricas, envolve uma grande quantidade de condicionantes e restrições, conforme cada contexto particular.

A Figura 9 ilustra possíveis soluções de plantas baixas esquemáticas que podem ser resultado da aplicação das regras da quarta etapa. Sobre esse exemplo é preciso fazer duas observações: primeiro, ele mostra duas soluções em planta com organizações espaciais aparentemente tradicionais, mas que é fruto da aplicação analógica das regras, o que limita a capacidade da gramática em gerar organizações mais singulares ; segundo, para se chegar a essas soluções espaciais é preciso a aplicação das regras dimensionais - etapa ainda em desenvolvimento. No entanto, sabendo que estes exemplos apresentam um vácuo de informações de como se chegar a esses resultados, alguns testes já evidenciam que é possível obter diferentes soluções levando-se em consideração fatores como o formato côncavo ou convexo - tanto do limite da habitação, quanto do limite dos ambientes, variação média da área de cada ambiente individualmente, proporção da dimensão entre ambientes adjacentes (se $1 / 2,1 / 3$ ou $2 / 3$ da dimensão total da parede que os separa), tipo de separação (se opaco, transparente ou parcial - no caso de cozinhas americanas), etc. 


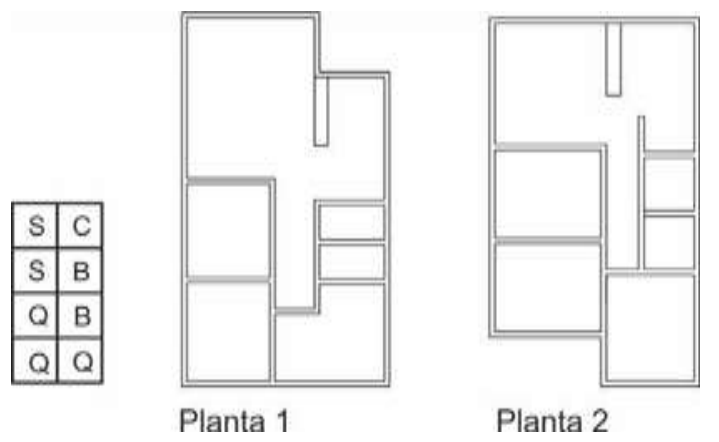

\section{CONSIDERAÇÕES FINAIS}

A obtenção de projetos de projetos de habitação de pequeno porte customizadas é um processo longo. São necessárias mudanças que abarcam não apenas o método projetual, mas também a maneira de gerir o processo de projeto e construção. Para realizar essa mudança paradigmática é indispensável, por um lado, uma metodologia projetual que esteja interessada não apenas na criação de projetos, mas principalmente no processo de criação desses projetos, como é o caso da abordagem do design generativo. Além disso, como sugere Machado (2007), na customização em massa, deve-se optar por um modelo de gestão totalmente orientado para o cliente - atitude que difere do modelo tradicional, o qual está orientado para o mercado e centrado diretamente no produto. Ou seja, é fundamental que haja a compatibilização entre a expertise do técnico e as demandas personalizadas do cliente e o design generativo entra como um instrumento metodológico que permite essa confluência de saberes com maestria.

Tendo em vista esse longo caminho que é preciso percorrer, este artigo apresenta uma contribuição em busca da reinterpretação do tradicional processo de projeto/construção de habitações de médio e pequeno porte. A etapa ora desenvolvida teve foco apenas na primeira fase (a analógica) do estágio 1, referente à definição da organização espacial genérica da habitação. Entretanto, mostra-se suficientemente rica, em termos de possíveis regras e variações formais, sendo eficaz em demonstrar seu potencial para a geração de plantas de habitação de pequeno porte customizadas.

Como sugere Eilouti (2019), as gramáticas da forma tratam de elementos morfológicos e relações geométricas, topológicas e numéricas entre esses elementos, que definem o processo que gera o projeto. As regras das três etapas aqui apresentadas mostram claramente como esses elementos são relacionados para definir o processo de projeto. E, mesmo tendo sido um experimento totalmente analógico, sem ainda ter finalizado a última etapa das regras, é possível perceber que sua aplicação permite gerar muitas organizações espaciais esquemáticas.

Por fim, vale reforçar que quando essa implementação, feita analogicamente, for desenvolvida com ajuda de tecnologias digitais, como as proporcionadas por softwares de programação, as soluções formais genéricas serão ainda mais otimizadas e automatizadas, resultando, por sua vez, em variados tipos de plantas customizadas. É dessa maneira que é possível unir conhecimento técnico e demandas individuais, proporcionando a participação desses dois atores nas definições do projeto de maneira mais eficaz.
Figura 8: Exemplos de plantas geradas a partir de uma mesma organização espacial esquemática.

Fonte: Os autores. 


\section{Agradecimentos}

Os autores agradecem à FACEPE (APQ-0495-6.04/14) e a CEO da startup PopBIM, Arquiteta Jeanne Karlla Barbosa.

\section{Referências Bibliográficas}

AMORIM, R.; TELLES, R. Reinventar: escritório modelo de arquitetura social. In: Revista Práxis: saberes da extensão, Paraíba, v.4, n.6, 2016. Disponível em: <http://periodicos.ifpb.edu.br/index.php/praxis/article/viewFile/576/355>. Acesso em: abr. 2018.

ARAVENA, A.; IACOBELLI, A. Elemental: manual de vivienda incremental y diseño participativo. Ostfildern: HatjeCantz, 2012.

BONDUKI, N. Política habitacional e inclusão social no Brasil: revisão histórica e novas perspectivas no governo Lula. In: Arq.urb - Revista eletrônica de arquitetura e urbanismo, 1, 2008. Disponível em: <http://www.usjt.br/arq.urb/numero 01/artigo 05 180908.pdf>. Acesso em: jun. 2012.

BRANDÃO, D. Disposições técnicas e diretrizes para projeto de habitações sociais evolutivas. In: Ambiente Construído, v. 11, n. 2, p. 73-96,abr./jun, 2011.

BUZZAR, M.; FABRICIO, M. Metodologia de avaliação do produto habitacional para o programa de arrendamento residencial. In: Encontro Nacional de Tecnologia do Ambiente Construído, 13, 2010, Canela. Anais... 2010.

CELANI, G.; CYPRIANO, D.; GODOI, G.; VAZ, C. A gramática da forma como metodologia de análise e síntese em arquitetura. In: Conexão - comunicação e cultura / Universidade de Caxias do Sul, Caxias do Sul, v. 5, n. 10, p. 180-197, 2006.

CELANI, C. Algorithmic Sustainable Design. Vitruvius, v.116, 2011. Disponível em: $<$ http://www.vitruvius.com.br/revistas/read/resenhasonline/10.116/3995>. Acesso em: 04 out, 2014.

DUARTE, J. Personalizar a habitação em série: Uma Gramática Discursiva para as Casas da Malagueira do Siza. Lisboa: Ed. Fundação Calouste Gulbenkian, 2007.

EILOUTI, B. Shape grammars as a reverse engineering method for the morphogenesis of architectural façade design. In: Frontiers of Architectural Research, 2019. Disponivel em: <https://doi.org/10.1016/j.foar>. Acessoem: 06 mar 2019.

ELOY, S. A transformation grammar-based methodology for housing rehabilitation: meeting contemporary functional and ICT requirements. 2012. Tese (PhD em Arquitetura). Universidade Técnica de Lisboa, Lisboa, 2012.

FIM, M.; SILVA, A.; BRAGA, B.; OLIVEIRA, H.; PEREIRA, J. H. AssitenciaTecnica Pública e gratuita para Habitação de Interesse Social: análise das condições arquitetônicas de residências de um bairro em Nova Venécia - ES. In: RevistalfesCiência. V. 5. N. 1, p. 11 -35, 2019.

FISCHER, T.; HERR, C. Teaching Generative Design. In: International Generative Art Conference, Generative Design, 4., 2015, Milão. Proceedings... Disponível em: <http://www.generativeart.com>. Acesso em: 14 abr 2015.

GRIZ, C; MENDES, L.; AMORIM, L.; HOLANDA, M. A.; CARVALHO, T.. O meu modo de morar: uma gramática para reformar projetos de apartamentos. In: XX Congresso Da Sociedade Ibero-Americana De Gráfica Digital - SIGRADI 2016, 2016, Buenos Aires. Proceedings..., 2016. v. 1. p. 687-693. 
KNIGTH, T. Shape grammars:SixTypes. In: Environment and Planning B: Urban Analytics and City Science, fev/1999.

KNIGTH, T. Shape grammars: SixTypes. In: Environment and Planning B: Urban Analytics and City Science, v. 26, n. 1, p. 15-31, fev. 1999.

KOLAREVIC, B. (Ed.). Architecture in the digital age: design and manufacturing. New York: Taylor e Francis, 2005. 320 p.

KOWALTOWSKI, K.; GRANJA, D.; MOREIRA, D.; PINA, S.; OLIVA, C.; CASTRO, M. The Brazilian Housing program 'Minha Casa Minha Vida' - A Systematic Literature Review. In: Journal of the Korean housing association, v. 26, p. 35-42, 2015.

LI, A. A shape grammar for teaching the architectural style of the Yingzaofashi. 2001. Dissertação MIT, Cambridge, 2001.

LIMA, E; VIEIRA, A; MENDES, L. T.; GRIZ, C. Houses for everybody? Brazilian competition: an application of shape grammar and space syntax for analyzing low-income housing. In: 35th eCAADe Conference - Education and Research in Computer Aided Architectural Design in Europe, 2017, Roma. Proceedings... Roma, 2017.

MACHADO. A. Customização em Massa na Construção Civil: novas estratégias ou antigas práticas? In: Encontro de Estudos em Estratégia, 3., 2007, São Paulo. Anais... 2007

MAYER, R. A gramática da habitação mínima. Análise do Projeto Arquitetônico de Interesse Social em Porto Alegre e Região Metropolitana. 2012. Tese (Doutorado em Arquitetura) - Universidade Federal do Rio Grande do Sul, Porto Alegre, 2012.

MENDES, L. Personalização de Habitação de Interesse Social no Brasil: o caso da implantação urbana em conjuntos habitacionais. 2014. Tese (Doutorado em Arquitetura e Urbanismo) - Faculdade de Engenharia Civil, Arquitetura e Urbanismo da Unicamp, Campinas, 2014.

MIRON, L.; MONTEIRO, D.; SILVA, M. Territorialidades em Habitação de Interesse Social. Uma abordagem por meio da Percepção dos Usuários. In: Arquisur Revista. Ano 9. N. 15, p. 66 - 83, 2019.

MITCHELL, W. J. Afterword: The design Studio of The Future. In CAAD Futures Proceedings... p. 479494. 1989.

MITCHELL, W. J. A Lógica na arquitetura. Campinas: Ed. Unicamp, 2008.

MUSSI, A. Os Padrões de Ampliação Espontânea de Interesse Social em Porto Alegre, RS, e Região Metropolitana: Uma Proposta de Aplicação da Gramática da Forma e Sintaxe Espacial. 2014. Tese (Doutorado em Arquitetura) - Universidade Federal do Rio Grande do Sul. Porto Alegre, 2012.

NABONI, R; PAOLETTI, I. Advanced Customization in Architectural Design and Construction. Milano: Springer, 2015.

NARDELLI, E. S. Tecnologia digital avançada na produção de Habitações de Interesse Social - HIS no Brasil, SIGRADI, 14, 2010, Bogotá. Proceedings... p.403-406.

PINTO, C.; BERNARDO, A.; FEIJÃO, A. Avaliação Pos Ocupação (APO) a qualidade na Habitação de Interesse Social (HIS). In: Conferencia Internacional da LARES, 17, 2017, São Paulo. Anais... 2017.

RANGEL, J. O Programa "Minha casa minha vida" e seus desdobramentos no local: um estudo da pequena cidade de Ponta de Pedras, Pará. 2011. Dissertação (Mestrado em Planejamento Urbano e Regional) - Universidade do Vale do Paraíba, São José dos Campos, 2011.

Gestão \& Tecnologia de Projetos 
Habitação de Interesse Social Generativa: A gramática da forma como instrumento

Cristiana Griz crisgriz@gmail.com

Thaciana Belarmino

thacianabelarminof@gmail.com

Julia Dutra

julialsdutra@hotmail.com
STINY, G.; GIPS, J. Shape grammars and the generative specification of painting and sculpture. In: IfipCongress, 7, 1976, Amsterdam. Proceedings... Disponível em: <http://www.shapegrammar.org/ifip/ifip1.html>. Acesso em: 05 nov 2014>.

STINY, G. Two exercises in formal composition. In: Environment and Planning B, v. 3, p. 187-210, 1976. 
Cristiana Griz, Thaciana Belarmino, Julia Dutra 